\title{
Vagal baroreflex activation resulting in acute coronary stent thrombus associated with myocardial infarction: a case report
}

\author{
Yan-Yan Jing ${ }^{\dagger}$, De-Cai Luan ${ }^{\dagger}$ and Liu-Dong Li ${ }^{*}$
}

\begin{abstract}
Background: Percutaneous coronary intervention with stenting in patients with coronary atheromatous stenosis carry an inherent risk of affecting the baroreflex-mediated regulation of hemodynamic alterations, especially for heart rate and blood pressure. To the best of our knowledge, the vagal baroreflex activation associated with acute coronary stent thrombosis in patients who have undergone percutaneous coronary intervention has not been previously reported.

Case presentation: In the present article, we report a case of a Chinese patient (a 75-year-old male) with coronary artery disease who presented with hemodynamic alterations as a complication of vagal baroreflex activation after implantation of overlapping stents, followed by stent thrombosis associated with myocardial infarction.

Conclusion: The patient's vagal baroreflex sensitivity increased after the coronary stenting procedure. He was successfully treated with intra-aortic balloon pump therapy. Because of its rarity, this case is being reported to emphasize the importance of using intra-aortic balloon pump therapy.
\end{abstract}

Keywords: Vagal baroreflex activation, Acute coronary stent thrombosis, Myocardial infarction

\section{Background}

Percutaneous coronary intervention (PCI) has become an important procedure for the treatment of myocardial infarction. Although autonomic activity, baroreflex sensitivity, and hemodynamic alterations resulting from vagal baroreflex activation (VBA) have been reported in patients who have undergone carotid angioplasty and stenting [1-3], there are few data available about the hemodynamic alterations resulting from VBA in PCI patients [4]. The present article reports the case of a patient who developed an acute stent thrombosis associated with myocardial infarction, which resulted from VBA after PCI. To the best of our knowledge, the autonomic activity, baroreflex sensitivity, and hemodynamic alterations resulting from VBA in patients treated with $\mathrm{PCI}$ have not been previously reported.

\footnotetext{
* Correspondence: winterlee@hotmail.com

${ }^{\dagger}$ Equal contributors

Department of Cardiology, Yuhuangding Hospital, Qingdao Medical College, Qingdao University, Yantai, Shandong Province, China
}

\section{Case presentation}

A 75-year-old Chinese man who had been experiencing chest pain for 10 years presented at our institution. He was moderately active, doing odd jobs around the house, and accelerating angina over the past 2 years. The patient had been taking aspirin, nifedipine for high blood pressure and metformin for diabetes mellitus type 2 for almost 10 years. He smoked one pack of cigarettes per day for about 40 years before quitting the previous year. His past history was remarkable for chronic obstructive pulmonary disease.

At the time of admission, the physical examination showed heart rate (HR), 67 beats/min (bpm); blood pressure (BP), 156/89 mmHg; and blood glucose, $6.85 \mathrm{mmol} / \mathrm{L}$. An electrocardiogram (ECG) showed a sinus rhythm with ST depression and T-wave inversion when chest pain occurred. A complete blood count and a basal metabolic profile were examined; the evaluation of kidney function, blood acid, base balance, and blood sugar levels showed that there were all within a normal range. The treadmill exercise test was positive, and showed ST depression on the ECG when chest pain or shortness of breath occurred. The patient's response to clopidogrel therapy was determined by 
testing for CYP450 genetic polymorphism, which showed non-resistance to such therapy. Testing for CYP450 genetic polymorphism was to predict response to clopidogrel [5].

The patient was prepared for coronary angiography (and stent placement if necessary). Before the procedure, the patient's spontaneous baroreflex sensitivity (BRS), heart rate variability (HRV), and blood pressure variability (BPV) were measured (Table 1). Six hours before the patient underwent coronary angiography, he was given $300 \mathrm{mg}$ aspirin and $300 \mathrm{mg}$ clopidogrel. An initial dose of heparin $(100 \mathrm{U} / \mathrm{kg})$ was intravenously given before the procedure; an additional dose of heparin at $500 \mathrm{U}$ would be given if the procedure lasted 1 hour. The activated clotting time was maintained at $325 \mathrm{~s}$.

The coronary angiogram was done through the radial approach. The angiogramrevealed a proximal $90 \%$ diffuse stenosis with calcification in the middle segment of the left anterior descending artery (Figure 1A), and 95\% stenosis with calcification in the left circumflex artery (Figure 1B). The right coronary artery was observed to have $>80 \%$ diffuse stenosis with heavy calcification and occlusion in the middle segment (Figure 1C).

Two overlapping sirolimus-eluting stents (Cypher; Cordis, Miami, USA.), mounted on a balloon catheter, were inserted without a gap into the left anterior descending artery (stents were $36 \mathrm{~mm}$ in length and $3 \mathrm{~mm}$ in diameter) and the left circumflex artery (stents $14 \mathrm{~mm}$ in length and $3 \mathrm{~mm}$ in diameter), respectively (Figure 2A). The stents were advanced into the narrowed section of the arteries. When the stents were positioned, the balloon was inflated. To ensure full expansion of the stents, the stent balloon was gradually inflated to 14 atm in 10 to 40 seconds. Because of chronic total occlusion in the right coronary artery, we attempted to pass a wire through the lesion but failed. Considering that collateral circulation was already present, we abandoned the stent placement into the right coronary artery. After the stenting procedure, the thrombolysis in myocardial infarction (TIMI) grade was 3 , and no cineangiographic characteristics of

Table 1 Heart rate, systolic/diastolic blood pressure, heart rate variability, blood pressure variability and spontaneous baroreflex sensitivity before and after coronary artery stenting

\begin{tabular}{lll}
\hline & Pre-stenting & Post-stenting \\
\hline HR (beats/min) & 67 & 39 \\
SBP $(\mathrm{mmHg})$ & 156 & 87 \\
DBP $(\mathrm{mmHg})$ & 89 & 52 \\
HRV $\left(\mathrm{ms}^{2}\right)$ & 1019 & 1728 \\
BPV $\left(\mathrm{mmHg}^{2}\right)$ & 10.1 & 16.8 \\
BRS $\left(\mathrm{ms} / \mathrm{mmHg}^{2}\right)$ & 7.2 & 12.6 \\
\hline
\end{tabular}

BPV: Blood pressure variability; BRS: Spontaneous baroreflex sensitivity; DBP: Diastolic blood pressure; HR: Heart rate; HRV: Heart rate variability; SBP: Systolic blood pressure. thrombus were present. The procedure was uneventful without a special condition for the patient.

Approximately 20 minutes after the procedure (18:40), the patient developed nausea, vomiting, sweating and slow breathing associated with diaphoresis and pale complexion. His blood pressure was $87 / 52 \mathrm{mmHg}$ and heart rate was $39 \mathrm{bpm}$. At that time, the patient was conscious and had no chest pain. No evidence of bleeding or hematoma was found. The ECG monitor showed no change in ST/T waves. The HRV and BRS were, however, found to be greatly elevated (Table 1 ) compared with the levels measured before stenting, suggesting VBA. After administration of $1.5 \mathrm{~L}$ intravenous saline with dopamine and atropine, the BP and HR slightly improved.

However, at 22:50, the patient complained of precordial chest pain and diaphoresis, and presented drowsy, cold and clammy extremities. His peripheral pulses were not palpable, and blood pressure was not recordable. The ECG monitors showed ST elevation in leads V1, V2, V3 and V4; reciprocal ST depression in leads I, aVL and aVF; and sinus bradycardia with first-degree heart block. The cardiac troponin I (cTnI) testing value was $0.06 \mathrm{ng} /$ $\mathrm{mL}$ (normal value $0.04 \mathrm{ng} / \mathrm{mL}$ ). A diagnosis of myocardial infarction associated with first-degree heart block and cardiogenic shock was made.

Immediately a repeat coronary angiogram was done through the femoral approach, and the left anterior descending and circumflex arteries, into which the stents had been placed, were reexamined. The angiogram revealed thrombotic occlusion of the planted stents (Figure 2B) in both the left anterior descending and circumflex arteries, with TIMI flow grades of 1 and 0 , respectively. The thrombus burden was graded as G3 in the circumflex artery and as G4 in the left anterior descending artery. No evidence of artery dissection was found.

An intra-aortic balloon pump (IABP) was immediately inserted. The TIMI flow grade showed no improvement after runs of aspiration in the two arteries; at that time the patient was still in cardiogenic shock. An intracoronary balloon was placed at the location where the thrombi adhered in the left anterior descending and circumflex arteries. While continuing counterpulsation of the IABP, the thrombi in the stents disappeared shortly afterward (Figure 2C). The patient was given tirofiban, aspirin, clopidogrel and heparin; the balloon counterpulsation was maintained until the patient's heart rate normalized and blood pressure stabilized. The patient was discharged with a normal echocardiographic evaluation, and was asymptomatic at follow-up.

\section{Discussion}

The hemodynamic alterations involving arterial baroreflex and cardiac autonomic control in patients undergoing with carotid angioplasty or stenting are extensively reported 

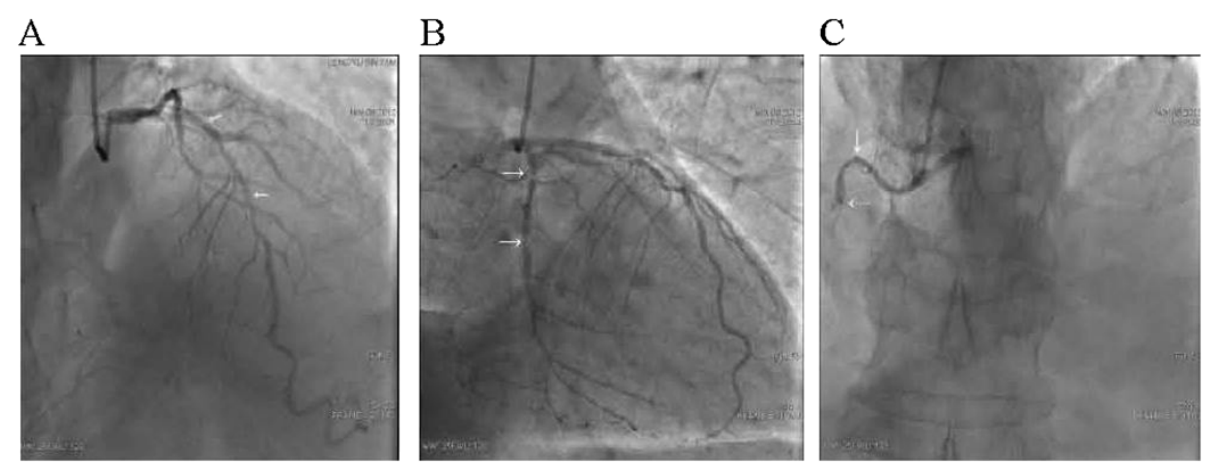

Figure 1 Coronary angiogram showing diffuse stenosis in the middle segments of the left anterior descending artery ( $A$, arrows), the left circumflex artery (B, arrows) and with occlusion in the right coronary artery (C, arrows).

[1-3]; conversely, there are few reports in patients who undergo PCI with angioplasty and stenting for coronary stenosis. In this study, we report that VBA caused hemodynamic alterations after a PCI procedure, followed by stent thrombosis associated with myocardial infarction. The patient was successfully treated with intra-aortic balloon counterpulsation. To the best of our knowledge, this is the first case describing VBA associated with acute coronary stent thrombosis after PCI.

In the clinical experience, patients developing VBA with bradycardia and hypotension during PCI procedure usually are instantaneous or last for a little while. Interestingly, our patient developed such hemodynamic alterations $20 \mathrm{mi}-$ nutes after the procedure. This extremely uncommon incident raised two questions: 1 ) whether the vagal stimulation resulted in the subsequent myocardial infarction or the myocardial infarction resulted in hemodynamic alterations; and 2) whether it might just be vice versa and the observed hemodynamic changes could be the result of a stent thrombosis.

The patient initially presented nausea, vomiting and slow breathing associated with diaphoresis and pale complexion, followed by bradycardia and hypotension. These symptoms typically result from vagal stimulation. Although occlusion might also activate cardiac vagal afferents, at that moment the patient had neither chest pain nor discomfort and showed no change in ECG. In addition to these clinical features, which excluded the possibility of myocardial infarction, measurements of BRS, HRV and BPV can be used to evaluate changes in baroreflex control and cardiac autonomic activity [1]. The results showed that the patient's BRS level increased, but his HR and BP levels decreased, suggesting the occurrence of VBA. The baroreflex is a very important regulatory mechanism for BP and HR [3]. Therefore, the initial hemodynamic alterations resulted from the stenting procedure and caused a subsequent stent thrombosis associated with myocardial infarction.

The stenting-caused hemodynamic alterations may be due to the effects of direct artery baroreceptor stimulation. Coronary stenting in patients with coronary atheromatous stenosis offers an opportunity to elucidate the cardiovascular autonomic response to direct intravascular stimulation of the baroreceptors. VBA development in patients undergoing coronary stenting could be due to distension of the coronary artery, which leads to stimulation of the baroreceptors, an increase in cardiac parasympathetic stimulation and a decrease in adrenergic output to the peripheral vasculature. The continuous
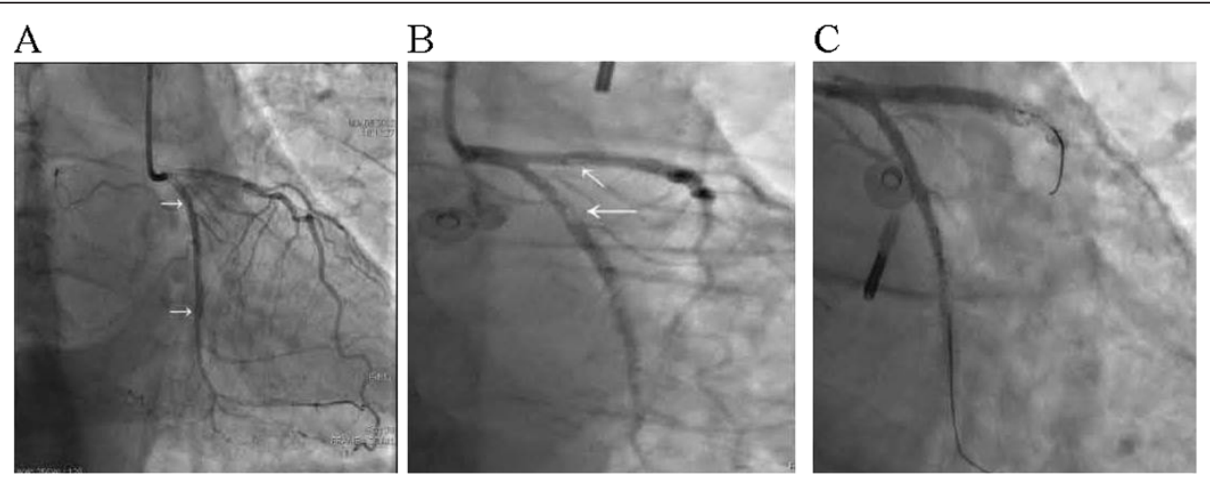

Figure 2 Coronary angiogram showing no stenosis following overlapping stent implantation ( $A$, arrows), thrombus in the stents in the anterior descending and circumflex arteries (B, arrows) and thrombus disappearing following intra-aortic balloon pump therapy (C). 
force to the vessel wall from the implanted stents increases vagal activity and baroreflex sensitivity. Stress and pain may also stimulate VBA, which affects hemodynamic stability and leads to nausea, vomiting, diaphoresis, paleness, decreasing blood pressure and/or drowsiness with cold and clammy extremities.

Our patient presented a series of clinical features of VBA resulting from the stenting procedure. The alterations in HR, BP, and breathing components were initially due to VBA because, at that moment, the patient showed no evidence of myocardial infarction, except for BRS and HR/BP levels in opposite manner. With continuing vagal activity and baroreflex sensitivity, the development of hemodynamic alterations, including hypotension and decreased blood flow in the coronary artery, was subsequently complicated by thrombosis in the implanted stents, as confirmed by the repeat angiogram. As a result of stent thrombosis or artery occlusion, myocardial infarction developed as confirmed by ECG and cTnI testing.

In consideration for VBA, it is necessary to exclude the possibility of cardiac tamponade, especially in a patient who has undergone PCI with stenting. The examination of BRS and HRV is a method of identifying patients at risk for cardiovascular disease associated with autonomic dysfunction [1]. In our patient, the opposite manner of BRS and HR/BP levels supported that the hemodynamic alterations resulted from VBA. Management of the VBA includes the expansion of blood volume and the administration of atropine, dopamine, and painkillers. These treatments generally relieve the patient's symptoms within a short period. However, our patient had a series of hemodynamic alterations, followed by thrombosis within the implanted stents. The thrombi in the stents resulted in myocardial infarction with cardiogenic shock, which was managed with IABP therapy.

IABP is an important therapy for increasing myocardial oxygen supply and decreasing myocardial oxygen demand [6], although its use is at the very least controversial. In our patient, IABP was used due to the failure of thrombus aspirations.

The overlapping stents might have contributed to the risk of thrombosis within the stents, resulting in myocardial infarction. Stenosis of the coronary artery is a main cause of myocardial infarction [7], because the smallest minimal luminal diameter is located within the zone of the stent overlap [8]. Therefore, the initial hemodynamic alterations caused by VBA were greatly associated with the subsequent stent thrombosis in our patient.

The mechanism of stent thrombosis is multifactorial factors [9]. Severe vagal stimulation is an important factor, which acts to lower heart rate, decrease blood pressure and slow blood flow, resulting in stent thrombosis or STelevation myocardial infarction. Myocardial reinfarction caused by stent thrombosis is associated with a larger thrombus burden [10,11], and stent thrombosis after primary PCI may be associated with a particularly poor prognosis [9]. Dual antiplatelet therapy with aspirin and clopidogrel is the standard care for most patients undergoing PCI [9]. Regarding clopidogrel therapy, more attention should be given to the conversion of CYP2C19 enzyme into its active metabolite $[9,5]$.

\section{Conclusion}

Coronary stenting caused an increase in baroreflex sensitivity and vagal activation in our patient. The patient's condition was complicated by stent thrombosis followed by myocardial infarction. The patient was successfully treated with intra-aortic balloon pump therapy. Because of its rarity, this case is being reported to emphasize the importance of using intra-aortic balloon pump therapy in patients such as ours.

\section{Consent}

Written informed consent was obtained from the patient for publication of this case report and any accompanying images. A copy of the written consent is available for review by the Editor-in-Chief of this journal.

\section{Abbreviations}

BPV: Blood pressure variability; BRS: Spontaneous baroreflex sensitivity; HRV: Heart rate variability; IABP: Intra-aortic balloon pump; PCl: Percutaneous coronary intervention; VBA: Vagal baroreflex activation.

\section{Competing interests}

The authors declare that they have no competing interests.

\section{Authors' contributions}

YYJ analyzed and interpreted the patient data. LDL and performed the examination of the patient's heart. YYJ and DCL were major contributors to the writing of the manuscript. All authors read and approved the final manuscript.

\section{Authors' information}

Yan-Yan Jing and De-Cai Luan share the first author.

\section{Acknowledgement}

The authors appreciate all participants who were involved in the management of the patients and the preparation of the manuscript.

Received: 11 April 2014 Accepted: 9 September 2014

Published: 27 September 2014

\section{References}

1. Acampa M, Guideri F, Marotta G, Tassi R, D'Andrea P, Giudice GL, Gistri M, Rocchi R, Bernardi A, Bracco S, Venturi C, Martini G: Autonomic activity and baroreflex sensitivity in patients submitted to carotid stenting. Neurosci Lett 2011, 491(3):221-226.

2. Mangin L, Medigue C, Merle JC, Macquin-Mavier I, Duvaldestin P, Monti A, Becquemin JP: Cardiac autonomic control during balloon carotid angioplasty and stenting. Can J Physiol Pharmacol 2003, 81(10):944-951.

3. Demirci M, Saribaş O, Uluç K, Cekirge S, Böke E, Ay H: Carotid artery stenting and endarterectomy have different effects on heart rate variability. J Neurol Sci 2006, 241(1-2):45-51.

4. Giglioli C, Tujjar O, Cecchi E, Landi D, Chiostri M, Valente S, Baldereschi GJ, Meucci F, Gensini GF, Romano SM: Hemodynamic changes acutely determined by primary PCI in STEMI patients evaluated with a minimally invasive method. World J Cardiovasc Dis 2013, 3(4). Article ID:34799, doi:10.4236/wjcd.2013.34A010. 
5. Ned RM: Genetic Testing for CYP450 Polymorphisms to Predict Response to Clopidogrel: current evidence and test availability. PLOS Currents Evidence on Genomic Tests 2010, Edition 1. doi:10.1371/currents.RRN1180.

6. Ryan TJ, Antman EM, Brooks NH, Califf RM, Hillis LD, Hiratzka LF, Rapaport E, Riegel B, Russell RO, Smith EE 3rd, Weaver WD, Gibbons RJ, Alpert JS, Eagle KA, Gardner TJ, Garson A Jr, Gregoratos G, Smith SC Jr: ACC/AHA Guidelines for the Management of Patients with Acute Myocardial Infarction: Executive Summary and Recommendations: A Report of the American College of Cardiology/American Heart Association Task Force on Practice Guidelines. Circulation 1999, 100:1016-1030.

7. Marella PC, Murarka S, Talluri SK, Bashir F: "Snake" Shaped Vegetation in Right Coronary Artery. N Am J Med Sci 2012, 8:373-375.

8. Räber $L$, Jüni $P$, Löffel L, Wandel $S$, Cook S, Wenaweser P, Togni M, Vogel R, Seiler C, Eberli F, Lüscher T, Meier B, Windecker S: Impact of stent overlap on angiographic and long-term clinical outcome in patients undergoing drug-eluting stent implantation. J Am Coll Cardiol 2010, 55(12):1178-1188.

9. Vlachojannis GJ, Claessen BE, Dangas GD: Early Stent Thrombosis after Percutaneous Coronary Intervention for Acute Myocardial Infarction. Intervent Cardiol 2012, 7(1):33-36.

10. Sianos G, Papafaklis MI, Daemen J, Vaina S, van Mieghem CA, van Domburg RT, Michalis LK, Serruys PW: Angiographic stent thrombosis after routine use of drug-eluting stents in ST-segment elevation myocardial infarction: the importance of thrombus burden. J Am Coll Cardiol 2007, 50(7):573-583.

11. van Werkum JW, Heestermans AA, de Korte Fl, de Korte Fl, Kelder JC, Suttorp MJ, Rensing BJ, Zwart B, Brueren BR, Koolen JJ, Dambrink JH, van't Hof AW, Verheugt FW, ten Berg JM: Long-term clinical outcome after a first angiographically confirmed coronary stent thrombosis: an analysis of 431 cases. Circulation 2009, 119(6):828-834.

doi:10.1186/1471-2261-14-131

Cite this article as: Jing et al: Vagal baroreflex activation resulting in acute coronary stent thrombus associated with myocardial infarction: a case report. BMC Cardiovascular Disorders 2014 14:131.

\section{Submit your next manuscript to BioMed Central and take full advantage of:}

- Convenient online submission

- Thorough peer review

- No space constraints or color figure charges

- Immediate publication on acceptance

- Inclusion in PubMed, CAS, Scopus and Google Scholar

- Research which is freely available for redistribution
C Biomed Central 